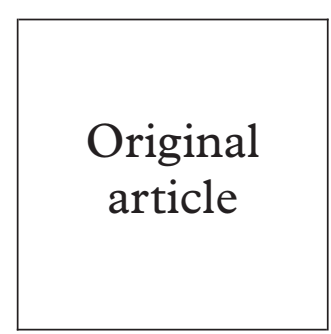

\section{Estimating the prevalence of Trichomonas vaginalis, Chlamydia trachomatis, Neisseria gonorrhoeae, and human papillomavirus infection in indigenous women in northern Australia}

\author{
Francis J Bowden, Barbara A Paterson, Jacki Mein, Jan Savage, Christopher K Fairley, \\ Suzanne M Garland, Sepehr N Tabrizi
}

\begin{abstract}
Objective: To estimate more accurately the age specific prevalence of Trichomonas vaginalis, Chlamydia trachomatis, Neisseria gonorrhoeae, and human papillomavirus infection (HPV) in indigenous women living in urban, rural, and remote areas of the "Top End" of the Northern Territory (NT).

Design: Analysis of data obtained from two community based studies using self administered tampon specimens tested by polymerase chain reaction for sexually transmitted disease (STD). Data pertaining to the notifiable STDs ( $N$ gonorrhoeae and $C$ trachomatis) were obtained from the NT health department.

Patients: 1090 indigenous women (age range 12-73 years) were enrolled when they attended local community health centres, family planning clinics, and STD clinics. The majority attended clinics in their home community in the course of "well women's checks" which encourage women to undergo screening for a variety of general medical conditions.

Results: The overall prevalence of $T$ vaginalis, $C$ trachomatis, $N$ gonorrhoeae, and HPV was 0.25 (95\% CI: $0.22-0.28), 0.11(0.09-0.13), 0.17(0.15-0.19)$, and $0.42(0.37-0.48)$ respectively. Of the women found to be infected (excluding HPV), $25.5 \%$ had two or more of the above organisms detected. There was a statistically significant increase in the age specific prevalence of $T$ vaginalis but a significant decrease with age for $C$ trachomatis and HPV infection. There was no statistically significant change for $N$ gonorrhoeae with age.

Conclusions: STDs are hyperendemic in this population of indigenous women and the notification data significantly underestimate their prevalence. Distinct patterns of age specific prevalence were demonstrated, highlighting the need to tailor control strategies to specific epidemiological features.

(Sex Transm Inf 1999;75:431-434)
\end{abstract}

Wellcome Trust Centre for the Epidemiology of Infectious Disease, Oxford University, Oxford

F J Bowden

Territory Health

Services, Casuarina,

NT, Australia

F J Bowden

B A Paterson

J Mein

J Savage

Department of Epidemiology and

Preventive Medicine, Monash University,

Alfred Hospital,

Prahran, Victoria

3181, Australia

C K Fairley

Royal Women's

Hospital and Royal

Children's Hospital

Health Care Network,

Department of

Microbiology and

Immunology and

Department of

Paediatrics, University

of Melbourne,

Victoria, Australia

S M Garland

S N Tabrizi

Correspondence to:

Francis J Bowden, Territory

Health Services, PO Box

40596, Casuarina, NT, 0811

Australia

Accepted for publication

26 August 1999

Keywords: sexually transmitted diseases; Australia; indigenous women

\section{Introduction}

The incidence of sexually transmitted diseases (STD) in the rural and remote populations of northern Australia is markedly higher than the Australian national average (Communicable Diseases Network-Australia New ZealandNational Notifiable Diseases Network, personal communication). We have suggested that one of the main reasons for this disparity is lack of access to, and utilisation of, diagnostic and treatment services in these areas. ${ }^{1}$ The design of appropriate indigenous health programmes to help to redress this imbalance must be guided by an understanding of the epidemiology of the diseases in question but there are few published community based data available to assist this process. Previous estimates of the burden of STDs in the Northern Territory (NT) have been based primarily on notification data which are collected by the NT health department. These data are derived from the public and private laboratories in the NT for Neisseria gonorrhoeae and Chlamydia trachomatis, and from a combination of clinician and laboratory sources for donovanosis and syphilis. Infections caused by Trichomonas vaginalis and human papillomavirus are not notifiable.
It is recognised that notification data can underestimate the true incidence of disease in a population for several reasons. In the case of STDs in small communities, people with symptoms may be reluctant to present for testing and, if they do, empirical therapy may be instituted without recourse to definitive diagnosis. In addition, as most STD infections are clinically silent, ${ }^{2}$ the bulk of disease detection is dependent on screening activities. Information obtained during such screening may not be recorded accurately in the notification data $^{3}$ and, as a result, marginalised subpopulations at particular risk of STDs may be systematically excluded from the reporting system. Case definitions may exclude disease cases if made too strict-for example, syphilis serology interpretation. Clinician based reporting systems may be very unreliable, even if disease is correctly diagnosed, because of workload issues and the low priority given to reporting responsibilities. Laboratory based reporting systems improve the case acquisition for some infections (for example, $N$ gonorrhoeae) but may still underestimate the prevalence of STDs which are diagnosed clinically (for example, genital warts), require potentially uncomfortable examinations 
Table 1 Proportion of women infected with Trichomonas vaginalis, Chlamydia trachomatis, Neisseria gonorrhoeae, and human papillomavirus by age group

\begin{tabular}{lllll}
\hline & $\begin{array}{l}\text { Trichomonas } \\
\text { vaginalis } \\
\text { (95\% CI) }\end{array}$ & $\begin{array}{l}\text { Chlamydia } \\
\text { trachomatis } \\
\text { (95\% CI) }\end{array}$ & $\begin{array}{l}\text { Neisseria } \\
\text { gonorrhoeae } \\
\text { (95\% CI) }\end{array}$ & $\begin{array}{l}\text { Human } \\
\text { papillomavirus* } \\
\text { (95\% CI) }\end{array}$ \\
\hline $11-15(\mathrm{n}=46)$ & $0.28(0.16-0.44)$ & $0.20(0.09-0.34)$ & $0.28(0.16-0.44)$ & $0.5(0.12-0.88)$ \\
$16-20(\mathrm{n}=218)$ & $0.18(0.13-0.24)$ & $0.15(0.11-0.21)$ & $0.17(0.12-0.23)$ & $0.62(0.47-0.76)$ \\
$21-30(\mathrm{n}=496)$ & $0.23(0.19-0.27)$ & $0.10(0.10-0.13)$ & $0.19(0.15-0.22)$ & $0.42(0.34-0.5)$ \\
$31-40(\mathrm{n}=215)$ & $0.29(0.23-0.35)$ & $0.09(0.05-0.13)$ & $0.13(0.08-0.18)$ & $0.41(0.3-0.53)$ \\
$>40(\mathrm{n}=115)$ & $0.40(0.31-0.49)$ & $0.05(0.02-0.11)$ & $0.14(0.08-0.21)$ & $0.23(0.12-0.37)$ \\
All ages $(\mathrm{n}=1090)$ & $0.25(0.22-0.28)$ & $0.11(0.09-0.13)$ & $0.17(0.15-0.19)$ & $0.42(0.37-0.48)$ \\
\hline
\end{tabular}

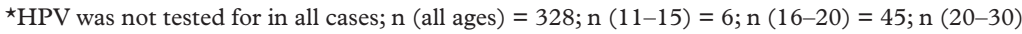
$=156 ; \mathrm{n}(31-40)=73 ; \mathrm{n}(>40)=48$.

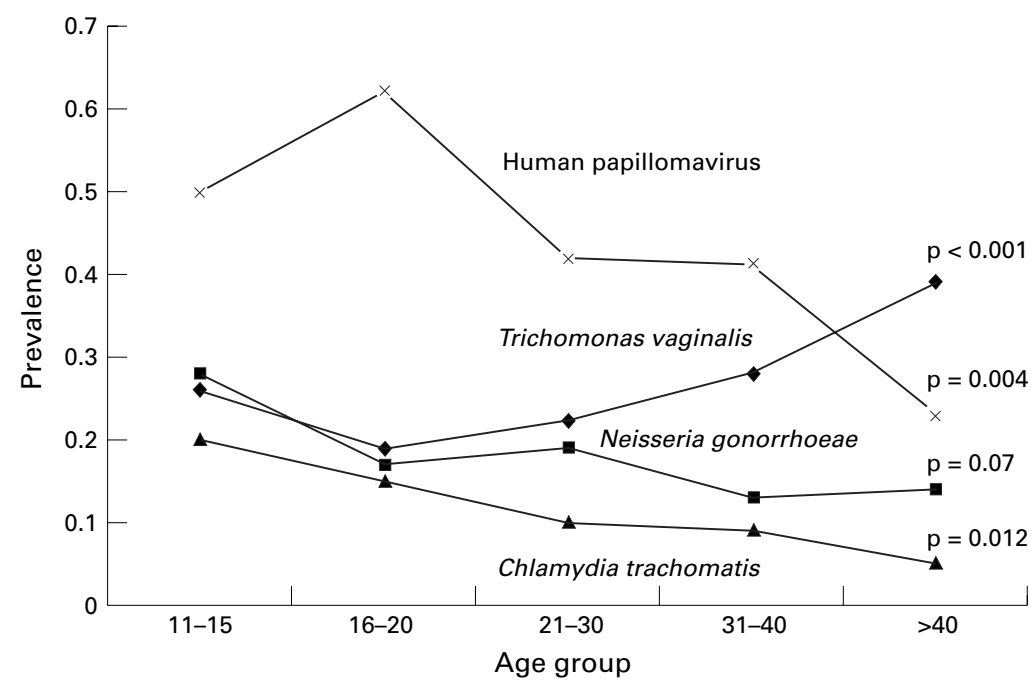

Figure 1 Comparison of age specific prevalence of $T$ vaginalis, $N$ gonorrhoeae, $C$ trachomatis, and human papillomavirus infections in indigenous women. ( $p$ Values refer to $\chi^{2}$ analysis of prevalence in individual age groups for each pathogen.)

for tests (for example, donovanosis), or where test sensitivity is poor (for example, gonococcal culture after delay in transport to a laboratory).

In recent years molecular amplification technologies such as polymerase chain reaction have enabled highly sensitive methods of detection of STDs using patient administered specimens such as tampons, ${ }^{4}$ swabs, ${ }^{5}$ and first void urine sampling ${ }^{6}$ to be carried out.

In this paper we present epidemiological data concerning indigenous women living in the NT derived from two studies undertaken to determine the acceptability and precision of new non-invasive and minimally invasive screening techniques. ${ }^{4}$ These data provide a more accurate estimate of the true prevalence of four STDs than the previously published notification figures.

\section{Methods}

Permission to undertake these studies was obtained from the relevant local ethics committee. The original study population consisted of women living in urban, rural, and

Table 2 Notifications of Chlamydia trachomatis and Neisseria gonorrhoeae in indigenous women in the NT, 1996* and estimated "true" number of cases in indigenous female population

\begin{tabular}{lllll}
\hline & $\begin{array}{l}\text { Number of } \\
\text { cases notified }\end{array}$ & Estimated incidencet & $\begin{array}{l}\text { Study } \\
\text { prevalence }\end{array}$ & $\begin{array}{l}\text { Estimated "true" } \\
\text { number of cases }\end{array}$ \\
\hline $\begin{array}{l}\text { Chlamydia trachomatis } \\
\text { Neisseria gonorrhoeae }\end{array}$ & 418 & $250 / 100$ 000/year & 0.11 & 2860 \\
& 623 & $370 / 100$ 000/year & 0.17 & 1840 \\
\hline
\end{tabular}

^Notification data from Disease Control, Territory Health Services, Darwin, NT.

†Population estimate of indigenous NT women $>14$ years of age derived from Australian Bureau of Statistics. ${ }^{8}$ remote regions of the so called "Top End" of the NT, a large geographical area encompassing the Darwin, Katherine, and East Arnhem regions.

Women were asked to participate in the study when they attended local community health centres, family planning clinics, and STD clinics. More than $80 \%$ of women attended clinics in their home community in the course of "well women's checks" which encourage women to undergo screening for a variety of general medical conditions.

Women were screened for $N$ gonorrhoeae, $C$ trachomatis, $T$ vaginalis, and human papillomavirus (HPV) by polymerase chain reaction (PCR) testing of a self inserted tampon. The methodology employed, described elsewhere, ${ }^{4}$ has been shown to be highly sensitive and specific and to be highly acceptable to the patient.

Notification data for 1996 were obtained from the notification records of Disease Control, Territory Health Services, Darwin. Demographic information was taken from the 1996 census, Australian Bureau of Statistics. ${ }^{8}$ $\chi^{2}$ calculations and $95 \%$ confidence intervals were calculated using EPI-INFO 6 software. ${ }^{9}$

\section{Results}

Results and demographic information were available for a total of 1090 indigenous women derived from over 20 different clinics and sites.

The overall prevalence of $T$ vaginalis, $C$ trachomatis, $N$ gonorrhoeae, and detectable HPV DNA was 0.25 (95\% CI: 0.22-0.28), 0.11 $(0.09-0.13), 0.17(0.15-0.19)$, and 0.42 $(0.37-0.48)$ respectively. Of the women found to have $T$ vaginalis, $C$ trachomatis, or $N$ gonorrhoeae, 0.25 had two or more of the above organisms detected (data not shown).

The age specific prevalence data are shown in table 1 and figure 1.

There was a statistically significant decrease in the prevalence with age of $C$ trachomatis $(p=0.012)$ and detectable HPV DNA $(\mathrm{p}=0.004)$ but this was not demonstrated for $N$ gonorrhoeae $(\mathrm{p}=0.07)$. There was a statistically significant increase in the prevalence of $T$ vaginalis with age $(\mathrm{p}<0.001)$.

Notification data for 1996 for $N$ gonorrhoeae and $C$ trachomatis are shown in table 2 . Using 1996 census data to obtain a denominator population of approximately 16500 indigenous women aged more than 14 years in the NT, the estimated incidence of these two infections using the notification data is 0.037 year and $0.025 /$ year respectively. ${ }^{8}$ The total prevalence for $N$ gonorrhoeae and $C$ trachomatis in the study population was 0.17 and 0.11 respectively. Assuming that the surveyed women were representative of the general population and that individuals could only be infected once per year, screening of all indigenous women in the NT would have detected a total of 2860 cases of gonorrhoea and 1840 cases of chlamydia, which is, respectively, 4.6 and 4.4 times more than the cases officially notified. 


\section{Discussion}

This study shows that four STDs, $N$ gonorrhoeae, $C$ trachomatis, $T$ vaginalis, and HPV, are endemic in indigenous women in the Top End of the NT. One study has shown the prevalence of $C$ trachomatis and/or $N$ gonorrhoeae in males in central Australia to be $20.9 \%{ }^{6}$

More than $80 \%$ of the women in this study underwent screening in the course of community based activities. Women living in remote and rural settings were encouraged to attend for a well women's check which includes screening for hypertension, diabetes, STDs, cervical and breast cancer. Only $9.2 \%$ of women attended because of symptoms. It is possible that this type of screening results in an underrepresentation of high risk women who, for a number of complex sociocultural reasons, may not attend under these circumstances, leading to an underestimation of the prevalence of some STDs.

It is noteworthy that more than $90 \%$ of the women involved in the study were unaware of any abnormal genital symptoms at the time of screening. ${ }^{10}$

Hyperendemic levels of $T$ vaginalis were detected in women in the Top End of the NT. Apart from the discomfort of symptomatic disease, $T$ vaginalis is associated with premature rupture of membranes and premature labour ${ }^{11}$ and may increase the transmission of HIV. ${ }^{12}$

The only other study of $T$ vaginalis in northern Australia estimated the prevalence in indigenous women at $10 \%$, based on laboratory records of conventional methods (culture and microscopy). ${ }^{13}$ Our study used a more sensitive diagnostic technique, and a more representative population sample, and estimated the prevalence to be $25 \%$, which is consistent with other studies in disadvantaged populations in which the prevalence ranges from $24.7 \%$ to $49 \% .^{14-18}$ In our studies $T$ vaginalis was detected in less than $1 \%$ of non-indigenous women (data not shown), most likely reflecting major differences in the opportunity for diagnosis and treatment and health seeking behaviour over many years between the two groups.

The increase in prevalence of the condition with age is of considerable interest as it is not seen in the other STDs. However, studies from the United States and Papua New Guinea have shown similar age specific prevalences, ${ }^{19} 20$ a feature consistent with a disease with a very long duration of infection. Before the development of metronidazole, trichomoniasis in women was considered to be a disease of indefinite duration if not treated with local vaginal therapies and volunteer inoculation studies in men showed that infection could persist for many months. ${ }^{21}$

The overall prevalence of infection with $C$ trachomatis was 0.11 , with a rate of 0.2 in $11-15$ year old group and 0.15 in the $16-20$ year old group, which fell to 0.05 in the $>40$ year old group. The difference between the 16-20 year old group and $>40$ year old group was statistically significant. As was expected, the prevalence was highest in the younger age groups (11-30). We have shown that pelvic inflamma- tory disease caused by $C$ trachomatis is an important problem in the $\mathrm{NT}^{22}$ and the high prevalence results of this study are therefore not surprising.

Neisseria gonorrhoeae was also common in the population sample with an overall prevalence of 0.17 but there were no statistically significant differences in prevalence observed in the different age groups.

A non-age stratified breakdown of the HPV subtypes found in this population has been published elsewhere. ${ }^{23}$ The analysis presented here suggests that detectable HPV DNA (a marker of HPV infection, one of the major risk factors for cervical neoplasia), is acquired early by indigenous women but prevalence slowly decreases with age.

Recently, a broadly based indigenous sexual health strategy which includes educational, diagnostic, and treatment components has been ratified by Australian governmental and community based organisations. ${ }^{24}$ Priorities for care in indigenous health are usually established by local health service providers. Since the official notification data may be underestimating the true incidence of $N$ gonorrhoeae and $C$ trachomatis by factors of 4.6 and 4.4 respectively, we believe that there is an urgent need to consider these new data when such priorities are set.

The authors gratefully acknowledge the assistance of Maree Dunn, the clinical and laboratory staff of Territory Health Services, the Royal Women's Hospital, Melbourne, Westerns Pathology and Queensland Medical Laboratories who were involved in this study. The study was funded in part by involved in this study. The study was funded in part by National Health and Medical Research Council project grant. Contributors: FJB, BAP, CKF, SMG, and SNT were responsible for the original design and conduct of the study; JM and JS provided additional data and assistance in the study. All author contributed to the writing of the paper.

1 Fairley CK, Bowden FJ, Gay NJ, et al. Sexually transmitted diseases in disadvantaged Australian communities [letter] fAMA 1997;278:117-8.

2 Hook EW, Handsfield HH. Gonococcal infections in the adult. In: Holmes KK, Mardh P-A, et al, eds. Sexually transmitted diseases. 3rd ed: New York: McGraw-Hill, 1999 : 451-66.

3 Mak D, McDermott R, Plant A, et al. The contribution of community health surveys to Aboriginal Health in the 1990s. Aust NZ F Pub Health 1998;22:645-7.

4 Tabrizi SN, Paterson B, Fairley CK, et al. A selfadministered technique for the detection of sexually transmitted diseases in remote communities. F Infect Dis 1997; 176:289-92.

5 Wawer MJ, McNairn D, Wabwire-Mangen F, et al. Self-administered vaginal swabs for population-based assessment of Trichomonas vaginalis prevalence [letter] Lancet 1995;345:131-2.

6 Skov SJ, Miller P, Hateley W, et al. Urinary diagnosis of gonorrhoea and Chlamydia in men in remote aboriginal communities. Med F A ust 1997;166:468-71.

7 Tabrizi SN, Paterson BA, Fairley CK, et al. Comparison of tampon and urine as self-administered methods of tampon and urine in the detection of Chlamydiads of matis, Neisseria gonorrhoeae and Trichomonas vaginalis in women. Int F STD AIDS 1998;9:347-9.

8 Australian Bureau of Statistics. Experimental estimates of the indigenous population 3230.0 1991-1996. 1997.

9 Dean A, Dean J, Combier D, Brendel K, et al. Epi-Info, version 6: a word processing database and statistics program for epidemiologists on microcomputers. Atlanta, GA Centers for Disease Control and Prevention, 1994.

10 Paterson BA, Tabrizi SN, Garland SM, et al. The tampon test for trichomoniasis: a comparison between conventional methods and a polymerase chain reaction for Trichomonas vaginalis in women. Sex Transm Inf 1998;74:136-9.

11 Cotch MF, Pastorek JG 2nd, Nugent RP, et al. Trichomonas vaginalis associated with low birth weight and preterm (n) Group. Sex Transm Dis 1997;24:353-60.

enhances HIV transmission:no longer a hypothesis. Lancet 1998; 351 (suppl III):5-7.

13 Voolmann T, Morey F, Rich G. Trichomoniasis is a problem in aboriginal women - fact or fiction? Venereology 1995;8: 34-6. 
14 Anosike JC, Onwuliri CO, Inyang RE, et al. Trichomoniasis amongst students of a higher institution in Nigeria. App Parasitol 1993;34:19-25.

15 Mabey DC, Lloyd-Evans NE, Conteh S, et al. Sexually transmitted diseases among randomly selected attenders a an antenatal clinic in the Gambia. Br $\mathcal{F}$ Vener Dis 1984;60: 331-6.

16 O Farrell N, Hoosen AA, Kharsany AB, et al. Sexually transmitted pathogens in pregnant women in a rural South African community. Genitourin Med 1989;65:276-80.

17 Klouman E, Masenga EJ, Klepp KI, et al. HIV and reproductive tract infections in a total village population in rural Kilimanjaro, Tanzania: women at increased risk. F Acquir Immune Defic Syndr Hum Retrovirol 1997;14: 163-8.

18 Passey M, Mgone CS, Lupiwa S, et al. Community based study of sexually transmitted diseases in rural women in the highlands of Papua New Guinea: prevalence and risk factors. Sex Transm Inf 1998;74:120-7.
19 Zigas V. An evaluation of trichomoniasis in two ethnic groups in Papua New Guinea. Sex Transm Dis 1977;4:63-5 20 Burch TA, Rees CW, Reardon LV. Epidemiological studies on human trichomoniasis. Am f Trop Med Hyg 1959;8:312-18. 21 Lanceley F, McEntegart MG. Trichomonas vaginalis in the male. The experimental infection of a few volunteers. Lancet 1953;i:668-71. 22 Mein J, Bowden FJ. A profile of inpatient STD-related pel-
vic inflammatory disease in the Top End of the Northern Territory of Australia. Med F Aust 1997;166:464-7.

23 Bowden FJ, Tabrizi S, Paterson BA, et al. Determination of the prevalence of genital human papillomavirus genotypes
in women in Northern Australia using a novel, selfadministered tampon technique. Int 7 Gynecol Cancer 1998;8:471-5

24 The government response to the report of the ANCARD Working Party on Indigenous Australians' Sexual Health. Canberra, ACT: Australian Government Publishing Service, 1997. 